\title{
The effects of the noncompetitive NMDA receptor antagonist MK 801 on DRL performance in rats
}

\author{
H. WELZL, S. BERZ, and K. BÄTTIG \\ Laboratory of Behavioral Biology, Federal Institute of Technology, Zurich, Switzerland
}

\begin{abstract}
When rats were under a DRL 10 -sec schedule and had to rely on internal cues for obtaining food, the noncompetitive NMDA receptor antagonist MK $801(0.20$ and $0.25 \mathrm{mg} / \mathrm{kg})$ increased response rate (number of leverpresses/session) and decreased the efficiency in obtaining reward in a dose-dependent fashion. MK 801 shifted the median of the interresponse time interval (IRT) distribution to the left (shorter intervals) and increased the number of short IRT intervals $(0-2 \mathrm{sec})$ generated. When the end of the 10-sec interval in a DRL 10-sec schedule was signaled by an S+ (light), saline-injected, as well as MK 801-injected, animals improved their performance. Furthermore, the effect of MK 801 on response rate was less pronounced, and no shift in the median of the IRT distribution could be seen. A high dose of MK $801(0.30 \mathrm{mg} / \mathrm{kg})$ dramatically decreased response rate and efficiency independent of the presence of the $\mathrm{S}+$.
\end{abstract}

Noncompetitive N-methyl-D-aspartate (NMDA) receptor antagonists, such as ketamine, PCP, and MK 801, are known to influence a variety of sensory, motor, and cognitive functions (see, e.g., Alessandri, Bättig, \& Welzl, 1989; Morris, Anderson, Lynch, \& Baudry, 1986; Welzl, Alessandri, \& Bättig, 1990; Whishaw \& Auer, 1989). These behavioral effects of NMDA receptor antagonists seem to be due to their ability to block NMDA receptors in the central nervous system. NMDA receptors can be found throughout the brain with especially high concentrations in telencephalic structures (Monaghan \& Cotman, 1985). The brain structure with the highest content of NMDA receptors is the hippocampus. Thus, it might be expected that blockade of NMDA receptors in the brain, including those in the hippocampus, would disturb functions such as spatial and temporal discrimination learning in which the hippocampus plays a crucial role (e.g., Clark \& Isaacson, 1965; Handelmann \& Olton, 1981; Nonneman, Voigt, \& Kolb, 1974; Tonkiss, Morris, \& Rawlins, 1988; however, see Sinden, Rawlins, Gray, \& Jarrard, 1986). Indeed, blockade of NMDA receptors has been shown to impair spatial learning (e.g., Alessandri et al., 1989; Morris et al., 1986). Furthermore, chronic infusion of the competitive NMDA receptor antagonist AP5 into the ventricles of rats impaired the acquisition of a DRL task (Tonkiss et al., 1988).

MK 801 was a generous gift from Merck Sharp and Dohme. We thank J. A. Nagel for critically reviewing and editing a previous draft of this paper and $R$. Rettenbacher for carrying out a preliminary study. This research was supported by Grant 3.184-0.88 from the Swiss National Foundation. Correspondence should be addressed to $\mathrm{H}$. Welzl, ETH, Laboratory of Behavioral Biology, Tumerstrasse 1, CH-8092 Zürich, Switzerland.
The effect of acute blockade of NMDA receptors on signaled and unsignaled DRL performance has not been tested. Therefore, in the present study, we investigated how the noncompetitive NMDA receptor antagonist MK 801 affects performance of rats under a DRL 10-sec schedule. This schedule is in its unsignaled form dependent on a correct use of internal stimuli by the animal. Preliminary data were presented at the European Behavioral Pharmacology Society meeting in Noordwijkerhout (NL) in 1989.

\section{METHOD}

\section{Subjects}

Twenty-four male Wistar rats (Füllingsdorf, Switzerland), weighing 280-300 g at the beginning of the experiment, were housed in groups of 4 per cage (Makrolon), with free access to water throughout the experiment. They were kept in an animal room maintained at about $20^{\circ} \mathrm{C}$ and on a 12:12-h light:dark cycle, with lights on from $0600 \mathrm{~h}$ to $1800 \mathrm{~h}$. Food was available daily during training sessions, and additional food was available in the home cage between $1700 \mathrm{~h}$ and $1800 \mathrm{~h}$, so that the weight of the animals remained between $85 \%$ and $90 \%$ of their free-feeding weight.

\section{Drug}

MK 801 ((+)-5-methyl-16,11-dihydro-5H-dibenzo[a,d] cycloheplen5,10-imine; Merck Sharp \& Dohme International) was dissolved in physiological saline. The rats were injected with 0.00 (saline control), $0.20,0.25$, or $0.30 \mathrm{mg} / \mathrm{kg}$ of MK $80130 \mathrm{~min}$ before test sessions.

\section{Procedure}

Experiment 1. All rass were first trained to obtain food pellets $(45 \mathrm{mg}$, Noyes) by leverpressing in an operant chamber $(28 \times 21 \times 21 \mathrm{~cm}$; Lafayette Instruments) inside a sound-attenuating box. The food tray was centered behind an opening in one cage wall. Inside the cage and to the left of the opening, a lever was attached $7.5 \mathrm{~cm}$ above the grid floor. A force of approximately $15 \mathrm{~g}$ was required for lever depression. The animals were trained daily (30-min training sessions) under a DRL 10-sec (differential reinforcement of low 
rates $10 \mathrm{sec}$ ) schedule for 10 to 12 weeks to reach an efficiency criterion (see below). In this task, a food-deprived animal has to suppress responding (leverpresses) for at least $10 \mathrm{sec}$ in order for the next response to be rewarded with a food pellet. Responses during the 10-sec interval will reset the timer and, thus, delay the availability of reward.

After reaching an efficiency score (number of reinforcements/ number of responses per 30-min sessions) equal to or larger than 0.50 for at least 3 days in a row, the animals were systematically injected with saline prior to the next two sessions in order to habituate them to the injection procedure. On the next day, the animals were randomly assigned to one of three groups ( $n=8 /$ group) and injected with 0.00 (saline control), 0.20 , or $0.25 \mathrm{mg} / \mathrm{kg} \mathrm{MK} 801$ before the session. After another three days with training sessions but no injections, the saline control group was injected with $0.30 \mathrm{mg} / \mathrm{kg}$ MK 801 before a test session, and 8 of the previously drug-injected animals served as saline-injected controls.

Experiment 2. A stimulus light $(\mathrm{S}+)$ was introduced into the operant chamber, signaling the end of an uninterrupted 10-sec interval and, thus, availability of reward. The same 24 animals were then trained under this schedule for 21 days. The trained rats were again injected with either saline or one of three doses of MK 801 $(0.20,0.25$, or $0.30 \mathrm{mg} / \mathrm{kg})$, as described for Experiment 1, with the same animals receiving the same doses as before.
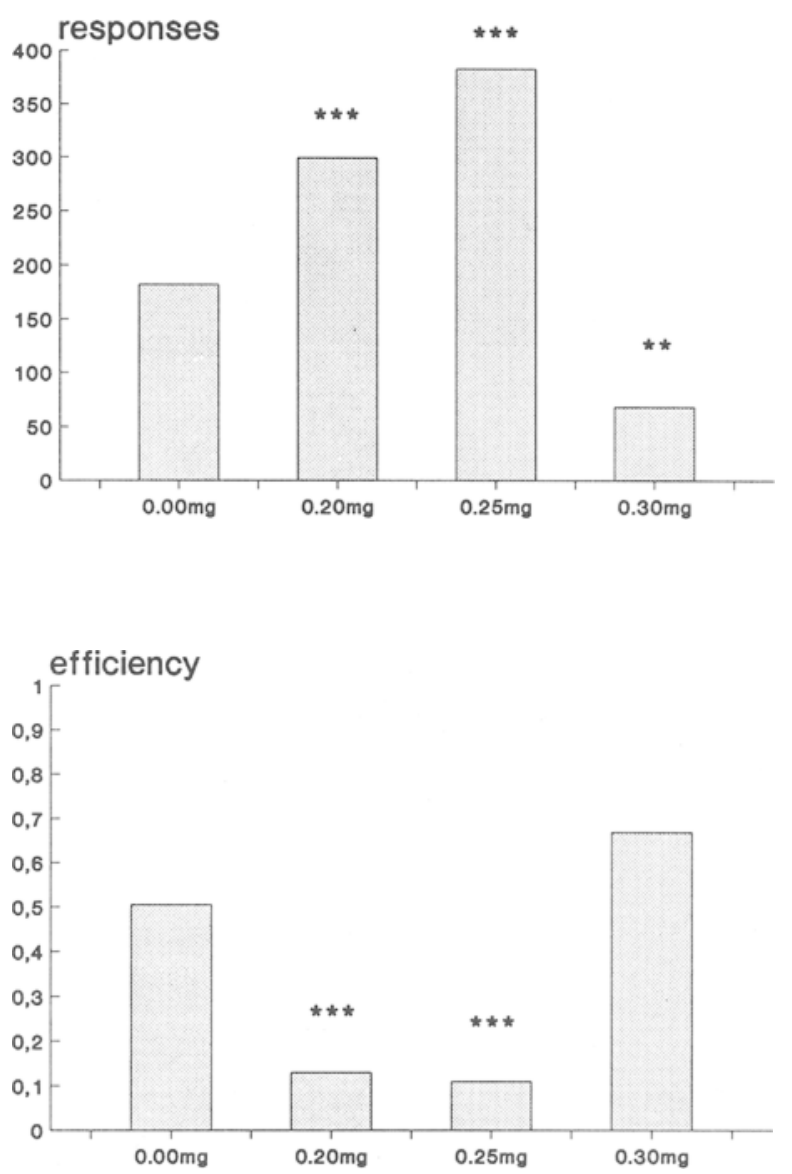

Figure 1. In a DRL 10-sec schedule, 0.20 and $0.25 \mathrm{mg} / \mathrm{kg}$ MK 801 increased, whereas a $0.30 \mathrm{mg} / \mathrm{kg}$ decreased, response rate (leverpresses $/ 30 \mathrm{~min}$; above). Efriciency (below) was decreased after systemic injection of 0.20 and $0.25 \mathrm{mg} / \mathrm{kg}$ MK 801 . Due to the large decrease in response rate, a dose of $0.30 \mathrm{mg} / \mathrm{kg}$ MK 801 did not change efficiency $(U$-test: $* *=.01 ; * * p=.001$ ).

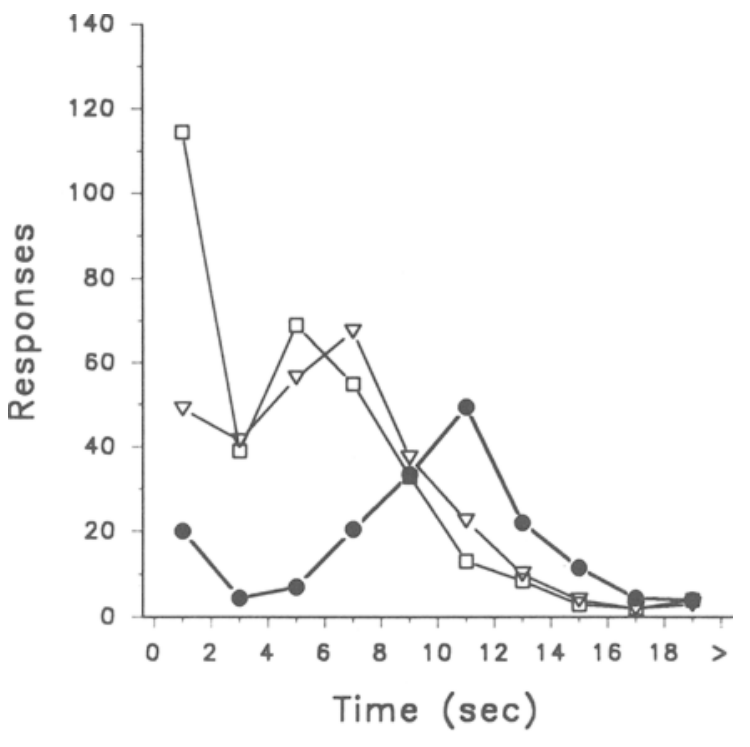

- $0.00 \mathrm{mg} / \mathrm{kg} \quad \nabla 0.20 \mathrm{mg} / \mathrm{kg} \quad \square \quad 0.25 \mathrm{mg} / \mathrm{kg}$

Figure 2. In a DRL 10-sec schedule, control animals preferentially paused for 10 to $12 \mathrm{sec}$ between responses and, therefore, the peak of their IRT frequency distribution fell into the 10-12-sec class. When 0.20 or $0.25 \mathrm{mg} / \mathrm{kg}$ was injected, the peak shifted to the $6-8-\mathrm{sec}$ or 4-6-sec class, respectively. Furthermore, a peak appeared in the 0-2-sec class. After injection of $0.30 \mathrm{mg} / \mathrm{kg}$ MK 801, response rate was greatly reduced, and no peak could be detected. The data of the $0.30 \mathrm{mg} / \mathrm{kg}$ group were therefore not included in this and the following graphs. All IRTs exceeding 10 sec were reinforced.

\section{Data Collection and Statistical Analysis}

In both experiments, response rate (leverpresses for food reward during a 30-min session), performance efficiency, and the distribution of interresponse times (IRTs) were calculated for individual test sessions. The median values of IRT frequency distributions (2-sec intervals) were calculated for each treatment group.

To further analyze IRT data, IRT frequency per opportunity (IRT/OP) was calculated (Anger, 1956). This analysis takes into account that each time a subject responds with a given IRT, the opportunity for a response with a longer IRT is precluded. Therefore, responses falling into a given IRT class are divided by the sum of all responses falling into this class and all longer IRT classes (for discussion, see Kramer \& Rilling, 1970). IRT/OP data represent the probability of emitting a response during a given IRT class. The data were submitted to an analysis of variance with drug treatment and IRT class as factors (BMDP).

Comparisons between saline- and drug-injected animals were made using the Mann-Whitney $U$-test. The sign test was used to compare response frequency and performance efficiency of salineand drug-injected animals before the introduction of the $S+$ with that after the introduction of the $S+$ (all $p$ values are two-sided; Siegel, 1956).

\section{RESULTS}

MK $801(0.20$ and $0.25 \mathrm{mg} / \mathrm{kg})$ produced a slight motor ataxia affecting the hind legs of the animals (as observed by the experimenter). However, during drug-injection tests, all animals, except those from the $0.30 \mathrm{mg} / \mathrm{kg}$ group, ate the food pellets almost immediately after delivery. The 


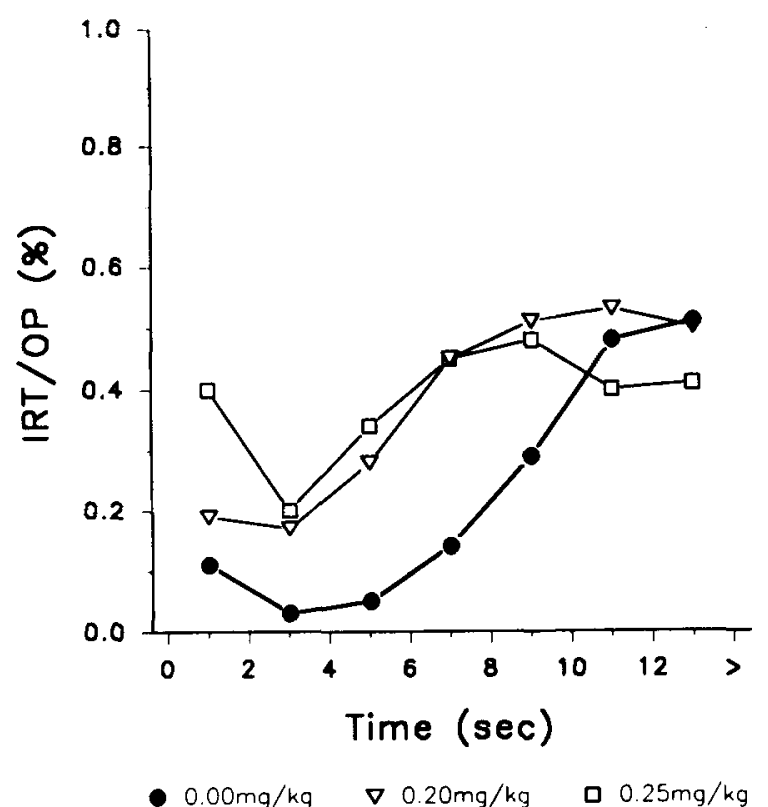

Figure 3. IRT/OP data for the saline group and the three druginjection groups. Compared with saline-injected controls, animals injected with MK $801(0.20$ and $0.25 \mathrm{mg} / \mathrm{kg})$ showed an increased probability to emit a response before the DRL requirement had been fulfilled. The response probability of animals injected with $0.30 \mathrm{mg} / \mathrm{kg}$ MK 801 was clearly reduced.

animals of the $0.30 \mathrm{mg} / \mathrm{kg}$ group approached the food tray but did not always eat the food pellet.

Expertment 1. A systemic injection of 0.20 or $0.25 \mathrm{mg} / \mathrm{kg}$ MK 801 before a DRL 10-sec session increased response rate with respect to the saline-injected group by $67 \%(p=$ $.001)$ and $113 \%(p=.001)$, respectively (Figure 1$)$. The same drug doses decreased performance efficiency by $74 \%$ and $78 \%(p s=.001)$ when compared with saline-injected control animals (Figure 1). A high dose of MK 801 $(0.30 \mathrm{mg} / \mathrm{kg})$ suppressed response rate substantially $(63 \%$; $p=.001$ ) and led to a concomitant $67 \%$ increase in performance efficiency $(p=.115$, n.s.).

The peak of the IRT distribution of saline-injected animals fell into the 10-12 sec class (Figure 2). The two lower doses of MK $801(0.20$ and $0.25 \mathrm{mg} / \mathrm{kg})$ shifted the peak of the IRT distribution to the left (6-8-sec and 4-6-sec classes), with an additional peak appearing at the shortest IRT interval (0-2-sec class). A dose of $0.30 \mathrm{mg} / \mathrm{kg}$ of MK 801 suppressed responding, and no clear peak could be detected. The IRT/OP data revealed that MK 801 shifted the response probability curve to the left (Figure 3$)$. The results could be confirmed with an analysis of variance [drug treatment $\times$ IRT class: $F(6,126)=$ 24.76, $p<.001]$.

For further analysis, the IRT frequency-distribution data were expressed as the percentage of maximum responses and plotted as a function of time relative to the median of the frequency distribution (i.e., peak interval). In addition to the above-described shift of the peak of the IRT frequency distribution, the superimposed distribution curves
(Figure 4) of control and drug-injected animals revealed an increase in the spread of the distribution that is positively correlated with the magnitude of the horizontal shift.

Experiment 2. Introducing an $\mathbf{S}+$ into the operant chamber that signaled the end of an uninterrupted $10-\mathrm{sec}$ interval attenuated the drug-induced increase in response rate (Figure 5). MK 801 doses of 0.20 and $0.25 \mathrm{mg} / \mathrm{kg}$ increased mean response rate by $38 \%$ and $20 \%$ ( $p$ s $=.007$ and .289 , respectively), but this increase was much smaller than that seen in the unsignaled DRL task. Thus, in the signaled DRL task, the response rate of rats injected with 0.20 or $0.25 \mathrm{mg} / \mathrm{kg} \mathrm{MK} 801$ was below that of the same rats in the unsignaled DRL task ( $p$ s $=.077$ and .013 , respectively).

Efficiency was increased in saline- and MK 801-injected $(0.20$ and $0.25 \mathrm{mg} / \mathrm{kg})$ animals when compared with the data obtained from the same groups in the unsignaled DRL task ( $p \mathrm{~s}=.013, .013$, and .23 ; Figure 5), but the saline control animals still performed better than the druginjected animals ( $p s=.005$ ). Response rate and efficiency of animals injected with $0.30 \mathrm{mg} / \mathrm{kg}$ MK 801 were not substantially changed by the introduction of the $S+$. Furthermore, the $S+$ prevented a shift in the peak of the IRT frequency distribution after injection of 0.20 or $0.25 \mathrm{mg} / \mathrm{kg}$ MK 801 (Figure 6). This result is also reflected in the IRT/OP data (Figure 7). Response probability began to increase in the 10-12 sec class in all groups. However, the increase was less pronounced in drug-treated animals [drug treatment $\times$ IRT class: $F(6,126)=20.56, p<.001]$.

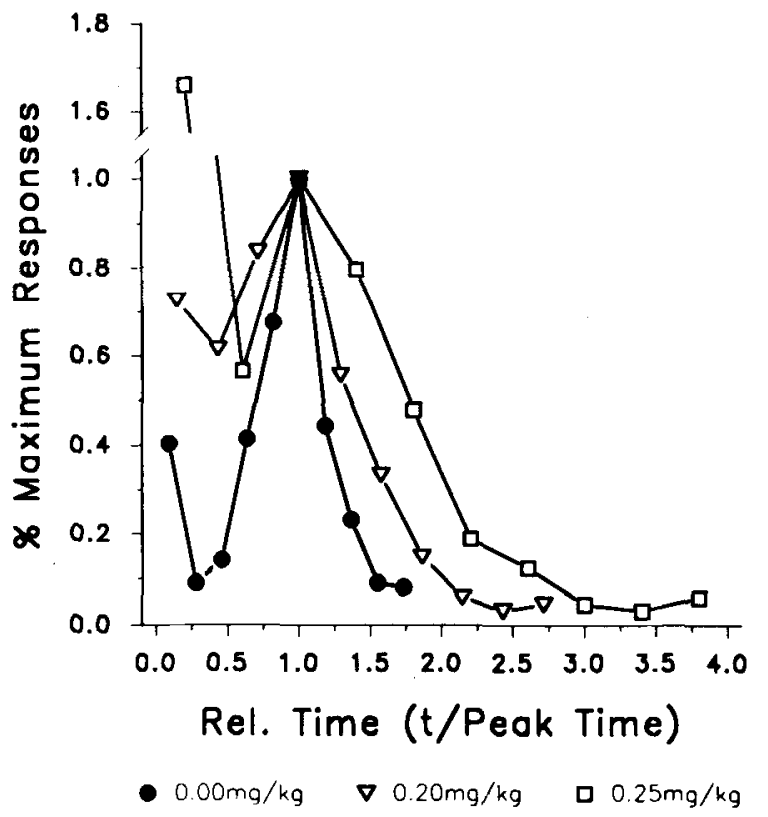

Figure 4. In the unsignaled DRL task, response frequencles per IRT interval of control and drug-injected $(0.20$ and $0.25 \mathrm{mg} / \mathrm{kg})$ animals were expressed as the percentage of maximum responses (peak interval). To allow superposition of the IRT frequencydistribution curves, the graphs were plotted with time relative to the peak interval. Note that for the $0.25 \mathrm{mg} / \mathrm{kg}$ group, the second peak was taken as the peak interval. 

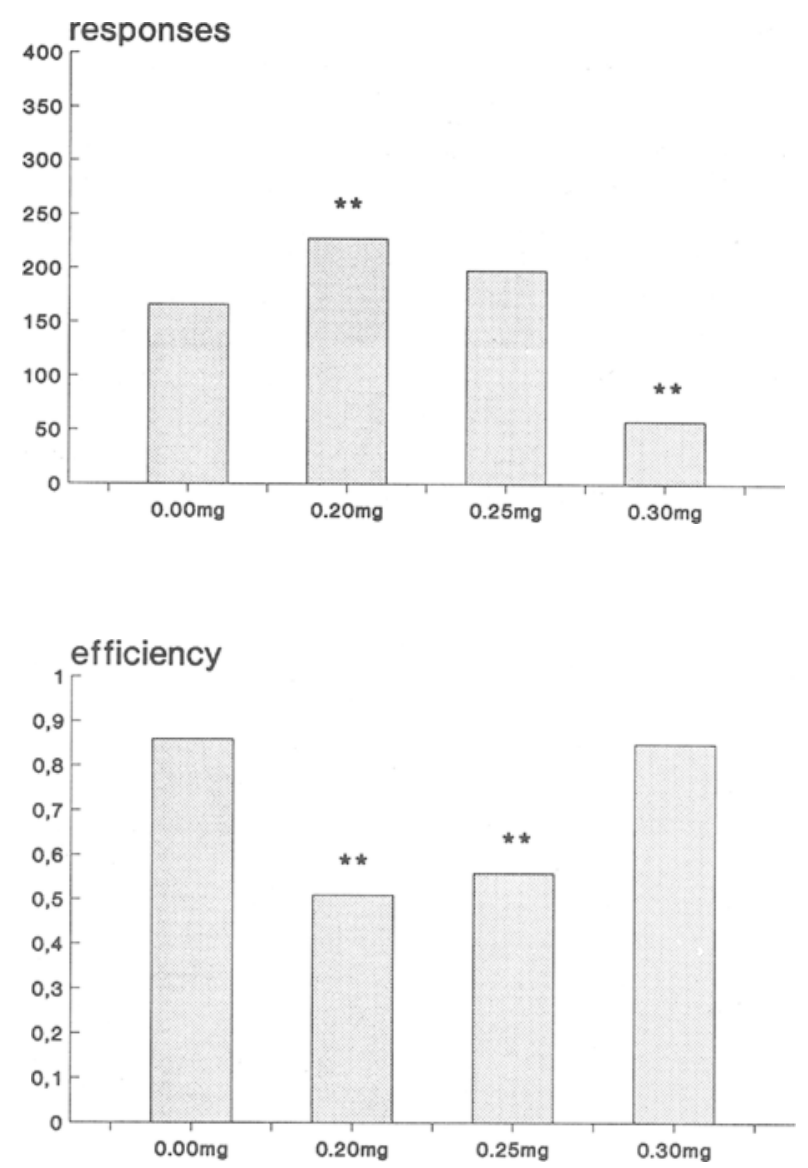

Figure 5. In a DRL 10 sec schedule, with a light signaling the end of an uninterrupted 10-sec interval (above), $0.20 \mathrm{mg} / \mathrm{kg}$ MK $801 \mathrm{in}$ creased response rate. The increase was smaller than that seen after MK 801 injections in the unsignaled DRL task. Introducing a stimulus light (below) improved efficiency in all four groups, but pretrial injection of MK $801(0.20$ and $0.25 \mathrm{mg} / \mathrm{kg})$ still reduced efficiency (U-test: $\left.{ }^{*} p=.01\right)$.

IRT frequencies were expressed as the percentage of maximum responses, and the resulting distribution curves of control and drug-treated animals were superimposed (Figure 8). The drug-injected animals showed an increase in the speed of the distribution without the accompanying horizontal shift of the peak interval observed in the unsignaled task described above.

\section{DISCUSSION}

The results suggest that in a DRL 10-sec paradigm, low doses of MK 801 both (1) increase response rate and (2) affect DRL performance, leading to a shift in the peak of the IRT distribution to the left. A high dose of MK 801 suppresses response rate.

The observation of an increase response rate (i.e., leverpresses in an operant chamber) after injection of MK 801 is in agreement with other studies describing increased activity in rats after injection of noncompetitive (MK 801: Ford, Norman, \& Sanberg, 1989; Whishaw \& Auer, 1989; ketamine: Alessandri et al., 1989) or competitive NMDA receptor antagonist (Boast \& Pastor, 1987). Although a role of dopamine in the nucleus accumbens in hyperactivity is well documented, it is not yet clear whether or not this system is also involved in MK 801-induced increase in activity. Some researchers have found that noncompetitive NMDA receptor antagonists increased dopamine metabolism in the nucleus accumbens (Carboni, Imperato, Perezzani, \& Di Chiara, 1989; Hernandez, Auerbach, \& Hoebel, 1988), whereas others using different techniques to measure dopamine metabolism have found no change in this area in response to noncompetitive NMDA receptor antagonists (Rao, Kim, Lehmann, Martin, \& Wood, 1990). Furthermore, lesions of the nucleus accumbens (Nabeshima et al., 1983) or monoamine depletion (Carlsson \& Carlsson, 1989) did not prevent the hyperactivity induced by the noncompetitive NMDA receptor antagonists phencyclidine or MK 801, respectively.

There are several possible explanations why rats could fail to perform successfully in a DRL schedule. This might be due to a general impairment of response inhibition that increases the incidence of all kinds of motor patterns, including leverpresses. Or it might be due to a more specific impairment that makes it difficult for animals to refrain from pressing a lever associated with food. Another possible explanation is a change in the ability to judge whether or not enough time has passed for the next leverpress to be reinforced. After an experimental manipulation, an animal might wait for too short or too long a time interval before pressing the response lever, or it might even

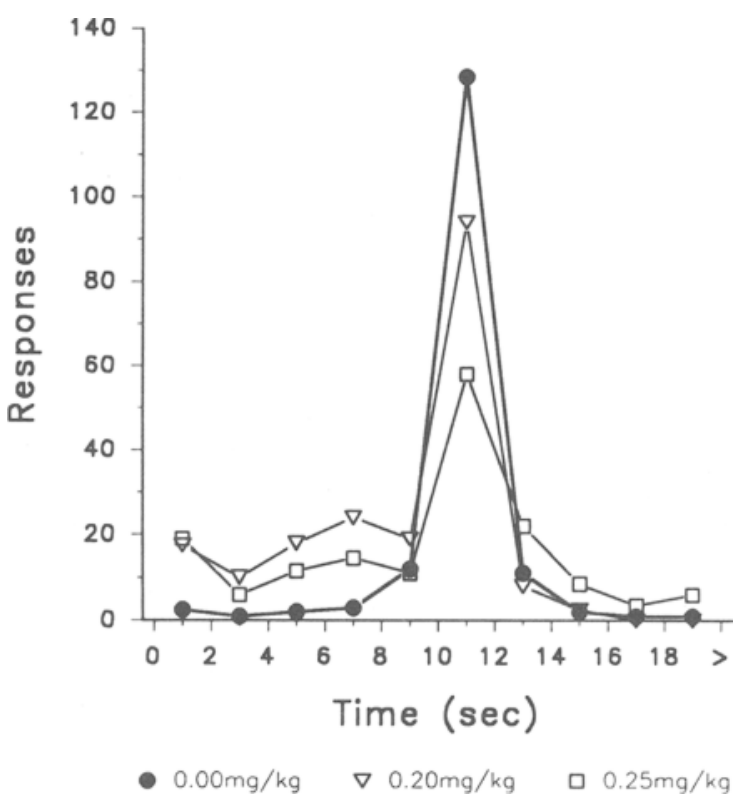

Figure 6. In a DRL 10-sec schedule, with a light signaling the end of the 10-sec delay, control animals and drug-injected animals showed a peak of their IRT frequency distribution in the 10-12-sec class. All IRTs exceeding 10 sec were reinforced. 


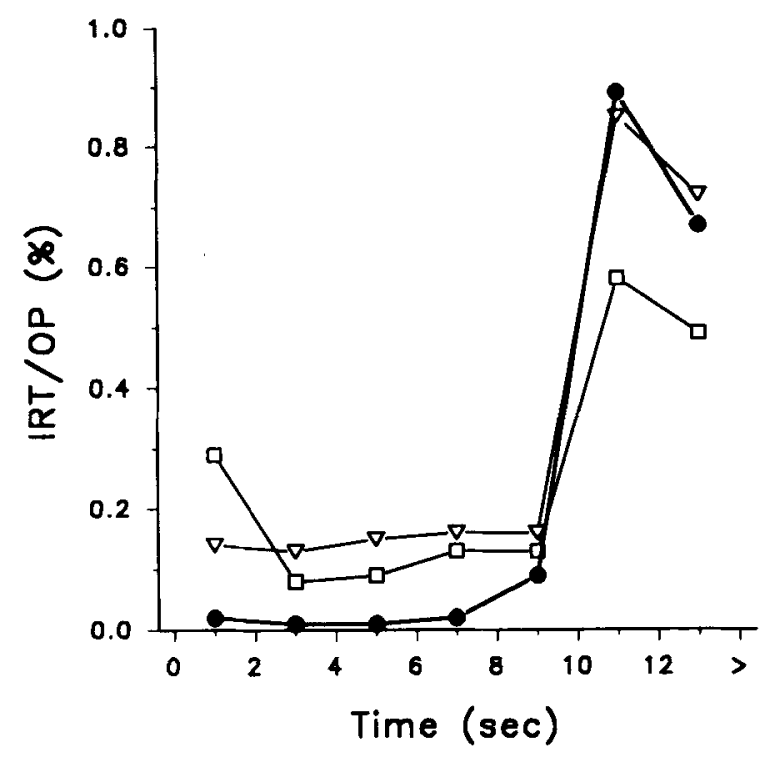

- $0.00 \mathrm{mg} / \mathrm{kg} \quad \nabla 0.20 \mathrm{mg} / \mathrm{kg} \quad \square 0.25 \mathrm{mg} / \mathrm{kg}$

Figure 7. IRT/OP data for the saline group and the three druginjection groups after the introduction of a light stimulus signaling the end of the DRL requirement. Both suline-injected and druginjected (0.20 and $0.25 \mathrm{mg} / \mathrm{kg}$ ) animals showed an increased probability to emit a response after the DRL requirement had been fulfilled and the signal light had been switched on. The response probability of animals injected with $0.30 \mathrm{mg} / \mathrm{kg}$ MK 801 was reduced.

press the lever at random intervals. All this will reduce its efficiency in obtaining reward.

In the unsignaled DRL task, the increased frequency of short IRT intervals in rats systemically injected with MK 801 is a sign of impaired response inhibition. The shift in the peak of the IRT frequency distribution to the left after systemic injection of MK 801 suggests an additional failure to correctly judge when a leverpress will be rewarded. However, although MK 801 caused an impairment in optimally spacing leverpresses, it did not prevent the development of a peak in the IRT frequency distribution, except with the highest dose. This implies that the animals still had a general idea of the task requirements. However, they expected the leverpress to be reinforced at an earlier point in time.

Introducing a light stimulus signaling the availability of food did not completely prevent the increase in responding observed in MK 801-treated animals. But the external stimulus did prevent the shift of the IRT frequency distribution. We therefore conclude that the drug-injected animals were able to solve the task with the help of an external cue. However, they were unable to solve the task on the basis of internal cues alone.

The effects of MK 801 on DRL resemble those observed after injection of amphetamine. Amphetamine has been reported to differentially affect performance under signaled and unsignaled conditions (Carey \& Kritkausky, 1972; Glick, Cox, \& Greenstein, 1975). During the unsignaled condition, the drug-induced response-rate increment was much greater than that during the signaled condition, and amphetamine shifted the peak of the IRT frequency distribution to the left, similar to the shift seen after MK 801 administration in our experiments. This amphetamineinduced shift of the IRT frequency-distribution peak has also been observed by several other investigators using a DRL procedure (e.g., Sanger, Key, \& Blackman, 1974; Sidman, 1955). When a discriminative stimulus signaled that a leverpress would now be rewarded, the amphetamineinduced increase in response rate was much smaller, and no shift of the IRT frequency-distribution peak occurred. This is identical to what we observed after the injection of MK 801 in our rats using a similar paradigm.

The high density of MK 801 binding sites in the hippocampus and neocortex (Wong, Knight, \& Woodruff, 1988 ) and the changes in glucose utilization in the hippocampus and neocortex induced by systemic injections of MK 801 (Kurumaji, Nehls, Park, \& McCulloch, 1989) suggest that MK 801 might exert its effects on DRL performance by acting on hippocampal and/or neocortical structures. The hippocampus and the septal area are anatomically and functionally closely linked structures, and their destruction repeatedly has been reported to attenuate DRL learning (see, e.g., Brookes, Rawlins, Gray, \& Feldon, 1983; Clark \& Isaacson, 1965; Ellen, Makohon, \& Richardson, 1978; Ellen, Wilson, \& Powell, 1964; Nonneman et al., 1974; Tonkiss et al., 1988). Impaired acquisition of DRL performance has also been reported after lesions in the mammillary bodies (Smith \& Schmaltz, 1979) and the habenular nucleus (Evans \& Thornton, 1984), both structures anatomically related to the septum and/or hippocampus. Cortical structures seem to contribute only little to DRL learning (Clark \& Isaacson, 1965;

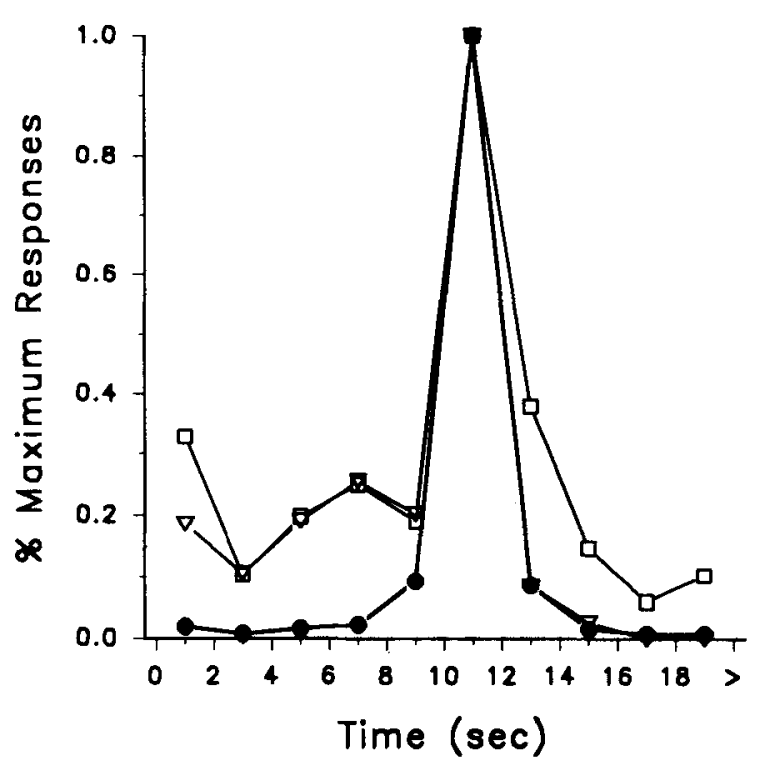

$0.00 \mathrm{mg} / \mathrm{kg} \quad \boldsymbol{\nabla} 0.20 \mathrm{mg} / \mathrm{kg} \quad \square \quad 0.25 \mathrm{mg} / \mathrm{kg}$

Figure 8. In the signaled DRL task, response frequencies per IRT interval of control and drug-injected $(0.20$ and $0.25 \mathrm{mg} / \mathrm{kg})$ animals were expressed as the percentage of maximum responses (peak interval). 
Finger et al., 1987; Nonneman et al., 1974; Schmaltz \& Isaacson, 1968; Welzl \& Bures, 1976).

In summary, the rats injected with MK 801 expected the leverpress to be reinforced at an earlier time than did the saline-injected control rats as expressed by a shift of the peak of the IRT distribution to the left. After the introduction of an external stimulus signaling availability of food reward, the DRL task no longer required the use of internal cues, and performance improved greatly in control and drug-injected rats. The effects of MK 801 on DRL performance resemble those of amphetamine on the same task.

\section{REFERENCES}

Alessandri, A., Bӥttig, K., \& Welzl, H. (1989). Effects of ketamine on tunnel maze and water maze performance in the rat. $B e-$ havioral \& Neural Biology, 52, 194-212.

ANGER, D. (1956). The dependence of interresponse times upon the relative reinforcement of different interresponse times. Joumal of $E x$ perimental Psychology, 52, 145-161.

Boast, C. A., \& PAstor, G. (1987). Characterization of motor activity patterns induced by N-methyl-D-aspartate antagonists in gerbils. Pharmacology, Biochemistry \& Behavior, 27, 553-557.

Brookes, S., Rawlins, J. N. P., Gray, J. A., \& Feldon, J. (1983). DRL performance in rats with medial or lateral septal lesions. Physiological Psychology, 11, 178-184.

Carboni, E., Imperato, A., Perezzani, L., Di Chiara, G. (1989). Amphetamine, cocaine, phencyclidine and nomifensine increase extracellular dopamine concentrations preferentially in the nucleus accumbens of freely moving rats. Neuroscience, 28, 653-661.

Carey, R. J., KritKausky, R. P. (1972). Absence of a responserate-dependent effect of $d$-amphetamine on a DRL schedule when reinforcement is signaled. Psychonomic Science, 26, 285-296.

Carlsson, M., \& Carlsson, A. (1989). The NMDA antagonist MK-801 causes marked locomotor stimulation in monoamine-depleted mice. Journal of Neural Transmission, 75, 221-226.

Clark. C. V. H., IsaAcson, R. L. (1965). Effect of bilateral hippocampal ablation on DRL performance. Journal of Comparative \& Physiological Psychology, 59, 137-140.

Ellen, P., Makohon, L., \& Richardson, W. K. (1978). Response suppression on DRL by rats with septal damage. Journal of Comparative \& Physiological Psychology, 92, 511-521.

Ellen, P., Wllson, A. S., \& Powell, E. W. (1964). Septal inhibition and timing behavior in the rat. Experimental Neurology, 10, 120-132.

Evans, J. A. C., Thornton, E. W. (1984). Impaired acquisition of DRL operant responding following lesion of the habenular nucleus. Physiological Psychology, 12, 220-226.

Finger, S., Altemus, K. L., Green, L., Wolf, C., Miller, J., \& ALMLI, C. R. (1987). Effects of medial frontal cortex lesions on DRL performance in rats. Physiology \& Behavior, 41, 387-389.

Ford, L. M., Norman, A. B., \& Sanberg, P. R. (1989). The topography of MK-801-induced locomotor patterns in rats. Physiology \& Behavior, 46, 755-758.

GLick, S. D., Cox, R. D., \& GReENSTEIN, S. (1975). Relationship of rats' spatial preferences to effects of d-amphetamine on timing behavior. European Journal of Pharmacology, 33, 173-182.

Handelmane, G. E., \& Olton, D. S. (1981). Spatial memory following damage to hippocampal CA3 pyramidal cells with kainic acid: Impairment and recovery with preoperative training. Brain Research, 217, 41-58.
Hernandez, L., Auerbach, S., \& Hoebel, B. G. (1988). Phencyclidine (PCP) injected in the nucleus accumbens increases extracellular dopamine and serotonin as measured by microdialysis. Life Sciences, 42, 1713-1723.

Kramer, T. J., * Rilung, M. (1970). Differential reinforcement of low rates: A selective critique. Psychological Bulletin, 74, 225-254.

Kurumaת, A., Nehls, D. G., PARK, C. K., \& MCCulloch, J. (1989). Effects of NMDA antagonists, MK 801 and CPP, upon local cerebral glucose use. Brain Research, 496, 268-284.

Monaghan, D. T., Cotman, C. W. (1985). Distribution of N-methylD-aspartate-sensitive $\mathrm{L}-\left[{ }^{3} \mathrm{H}\right]$ glutamate-binding sites in rat brain. Journal of Neuroscience, 5, 2909-2919.

Morris, R. G. M., ANderson, E., Lynch, G. S., \& BAudry, M. (1986). Selective impairment of learning and blockade of long-term potentiation by an N-methyl-D-aspartate receptor antagonist, AP5. Nature, 319, 774-776.

Nabeshima, T., Yamada, K., Yamaguchi, K., Hiramatsu, M., Furukawa, H., Kameyama, T. (1983). Effect of lesions in the striatum, nucleus accumbens and medial raphe on phencyclidineinduced stereotyped behaviors and hyperactivity in rats. European Joumal of Pharmacology, 91, 455-462.

Nonneman, A. J., Volgt, J., \& KolB, B. E. (1974). Comparisons of behavioral effects of hippocampal and prefrontal cortex lesions in the rat. Journal of Comparative \& Physiological Psychology, 87, 249-260.

RAo, T. S., KIM, H. S., Lehmann, J., Martin, L. L., Wood, P. L. (1990). Interactions of phencyclidine receptor agonist MK-801 with dopaminergic system: Regional studies in the rat. Joumal of Neurochemistry, 54, 1157-1162.

SAnger, D. J., Key, M., Blackman, D. E. (1974). Differential effects of chlordiazepoxide and d-amphetamine on responding maintained by a DRL schedule of reinforcement. Psychophamacology, 38, 159-171.

Schmaltz, L. W., IsaAcson, R. L. (1968). Effects of caudate and frontal lesions on retention and relearning of a DRL schedule. Journal of Comparative \& Physiological Psychology, 65, 343-348.

Sidman, M. (1955). Technique for assessing the effects of drugs on timing behavior. Science, 122, 925.

SIEGEL, S. (1956). Nonparametric statistics. New York: McGraw-Hill. Sinden, J. D., Rawlins, J. N. P., Gray, J. A., Jarrard, L. E. (1986). Selective cytotoxic lesions of the hippocampal formation and DRL performance in rats. Behavioral Neuroscience, 100, 320-329.

Smith, R. F., Schmaltz, L. W. (1979). Acquisition of appetitively and aversively motivated tasks in rats following lesions of the mammillary bodies. Physiological Psychology, 7, 43-48.

Tonkuss, J., Morris, R. G. M., Rawuns, J. N. P. (1988). Intraventricular infusion of the NMDA antagonist APS impairs performance on a non-spatial operant DRL task in the rat. Experimental Brain Research, 73, 181-188.

Welzl, H., Alessandr, A., BÄttig, K. (1990). The formation of a new gustatory memory trace in rats is prevented by the noncompetitive NMDA antagonist ketamine. Psychobiology, 18, 43-47.

Welzl, H., \& BuREs, J. (1976). Non-lateralization of a temporal discrimination task acquired under unilateral cortical spreading depression. Neuroscience Letters, 3, 71-74.

Whishaw, I. Q., \& AUER, R. N. (1989). Immediate and long-lasting effects of MK-801 on motor activity, spatial navigation in a swimming pool and EEG in the rat. Psychopharmacology, 98, 500-507.

WoNG, E. H. F., KNIGHT, A. R., \& WoOdRuF, G. N. (1988), [ $\left.{ }^{3} \mathrm{H}\right] \mathrm{MK}-801$ labels a site on the N-methyl-D-aspartate receptor channel complex in rat brain membranes. Journal of Neurochemistry, $\mathbf{5 0}$, 274-281.

(Manuscript received December 19, 1990; revision accepted for publication May 17, 1991.) 